\title{
Energy [r]evolution 2050 - Der Weg zu einer sauberen Energiezukunft für Österreich
}

\section{Die Zukunft ist erneuerbar ${ }^{1}$}

\author{
A. Egit, J. Westerhof
}

Das nennt man Perspektive: 2050 versorgt sich Österreich fast ausschließlich mit erneuerbaren Energien und schafft es, im Vergleich zu 2008 mehr als $90 \%$ der $\mathrm{CO}_{2}$-Emissionen einzusparen. All das, ohne einen Funken Lebensqualität zu verlieren.

Welche Maßnahmen und Weichenstellungen heute notwendig sind, um diese Perspektive zu erreichen, zeigt die Studie energy [r]evolution 2050, die Greenpeace gemeinsam mit dem Energieversorger EVN und der Gewerkschaft vida initiiert hatte und die vom Institut für Höhere Studien umgesetzt wurde (siehe Abb. 1 und 2).

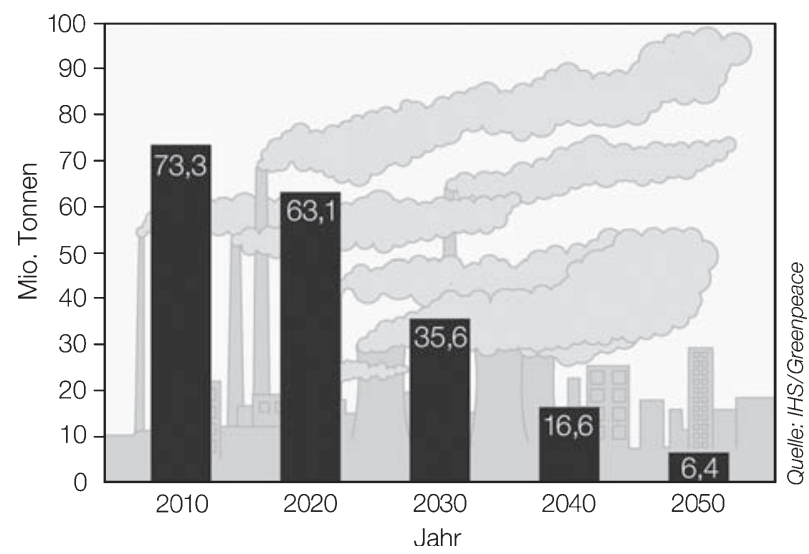

Abb. 1. Entwicklung der $\mathrm{CO}_{2}$-Emissionen in Österreich

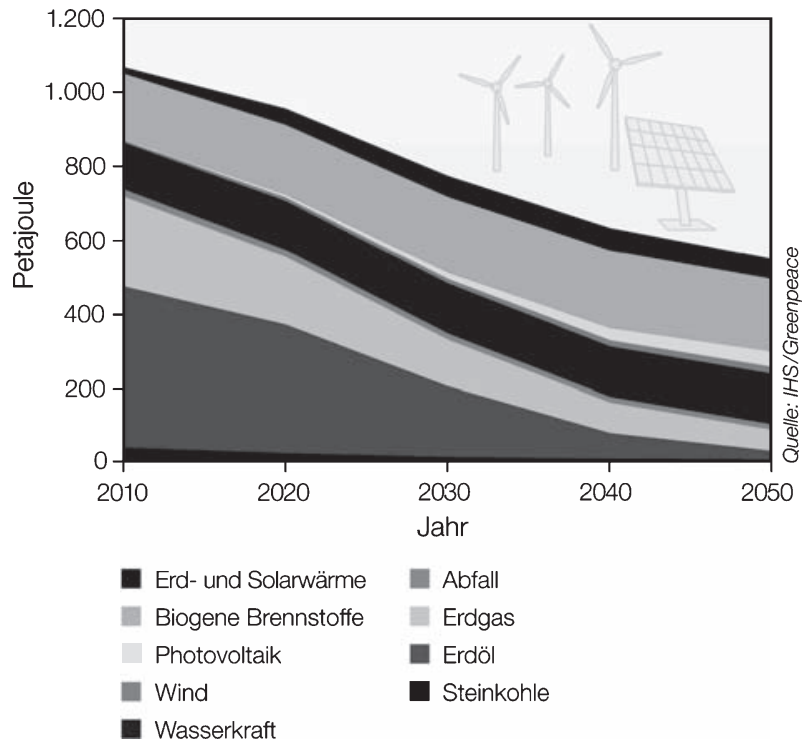

Abb. 2. Entwicklung des Energieverbrauchs in Österreich

\section{Nachhaltige Ansagen}

Das entwickelte Szenario prognostiziert bis 2050 eine Halbierung des Energieverbrauchs und eine Reduktion der Nutzung fossiler Energieträger in der Industrie auf einen Minimalanteil, obwohl gleichzeitig die Industrieproduktion ansteigt.

Die energy [r]evolution 2050 eröffnet zahlreiche Chancen auf neue Arbeitsplätze. Beispiele dafür sind die thermische Wohnraumsanierung und die Umstellung des Energiesystems.

Durch den Anstieg der Verkehrsleistung des öffentlichen Verkehrs von 24,3 auf 35 Milliarden Personenkilometer bei einem gleichzeitigen Rückgang des motorisierten Individualverkehrs ergibt sich ein hohes Potenzial an "Green Jobs".

Eine ähnliche Entwicklung ist auch im Güterverkehr notwendig: Die Studie beschreibt ein sinkendes Transportaufkommen und eine starke Ausweitung der Transportleistung per Bahn um fast $70 \%$.

\section{Effektives Maßnahmenbündel}

Nur mit einem Bündel an Maßnahmen können wir erreichen, dass wir im Jahr 2050 fossile Energieträger nur noch als Restbestände nutzen.

Effizienzsteigerungen führen $z u$ enormen Einsparungen beim Energieverbrauch: im Verkehr, bei Heizung und in der Industrie. Gleichzeitig muss der Anteil an erneuerbaren Energien kontinuierlich ausgebaut werden.

Eine Ökologisierung des Steuersystems muss dazu führen, dass menschliche Arbeit billiger und Energieverschwendung teurer wird, um letztlich eine Verhaltensänderung zu bewirken. Es bedarf der Festlegung verbindlicher Ziele für die Reduktion von Treibhausgasen. Eine "Sanierungsmilliarde" sorgt für neuen Schwung bei der thermischen Sanierung von Wohnungen und Häusern. Elektromobilität, ein starker Ausbau des öffentlichen Verkehrs und eine verkehrsvermeidende Raumordnung sind die zentralen Elemente in der Verkehrspolitik

Die Zukunft ist erneuerbar. Es braucht aber jetzt die notwendigen Entscheidungen, um dieses Ziel zu erreichen. Denn die Zukunft beginnt heute.

Die Studie steht Ihnen zum Download zur Verfügung unter: http://www. greenpeace.at/energy-revolution/.

Kurzfassung eines Vortrags der 49. Fachtagung der Österreichischen Gesellschaft für Energietechnik (OGE) im OVE, die am 20. und 21. Oktober 2011 in Innsbruck stattfindet.

Egit, Alexander, Mag., Geschäftsführer, Westerhof, Jurrien, Dipl.-Ing., Leiter der Klimakampagne, Greenpeace CEE, Fernkorngasse 10, 1100 Wien, Österreich (E-Mail: jurrien.westerhof@greenpeace.at) 